Open Access

\title{
Ageing in rural China: migration and care circulation
}

Jieyu Liu

\author{
Correspondence: \\ Jieyu.liu@soas.ac.uk \\ SOAS China Institute, SOAS \\ University of London, Thornhaugh \\ Street, Russell Square, London \\ WC1H OXG, UK
}

\begin{abstract}
This article applies the concept of care circulation (Baldassar and Merla, Transnational families, migration and the circulation of care: understanding mobility and absence in family life, 2013) to the processes involved in the care of old people in rural China, an area which has hitherto been predominantly located in a quantitatively based intergenerational transfer framework. Drawing upon a qualitative study of rural families in the context of rural to urban migration, this article examines the multidirectional and asymmetrical exchanges of caregiving and care-receiving and seeks to provide a more nuanced understanding of the impact of migration upon ageing and familial care in rural China. First, going beyond a unidirectional flow or two-way transfer, this article reveals that care circulates between different family members, in different locations, to differing degrees, over the life course. This circulation framework enables an examination of intra-generational dynamics as well as intergenerational relations. Second, this article draws attention to the mediating factors that impact upon the ways in which adult children care for the older generation. It reveals how the employment status of migrating adult children, the temporal dimension of migration and family life cycle of migrating children as well as family relations between the older generation and adult child generation are critical factors. These factors also contribute to the quality of care provided. Finally, while confirming existing scholarship that gender is an important dimension in structuring old age support in rural China, this article calls for a more differentiated approach among generations of women and between regions, revealing the ways in which local migration history interacts with intergenerational dynamics to determine the cohort of women that endure the greatest burden of care.
\end{abstract}

Keywords: Ageing, Care circulation, Migration, Intergenerational relations, Gender, Qualitative research, Rural China

\section{Background}

In China, family has traditionally been the primary institution responsible for providing care for older people. However, this 'traditional' model of familial support has come under pressure as China has entered a period referred to by some as 'super ageing' (Joseph and Phillips 1999). In 2014, the number of people in China who were 60 and over had reached 200 million (15\% of the population), with two thirds living in rural areas (Wang 2014). By 2050, this number is expected to exceed 400 million ( $35 \%$ of the population). What makes China different, and the challenges more acute, is the sheer number of people (almost $20 \%$ of the world's population), the stage of economic development and the relatively low-

(C) 2016 The Author(s). Open Access This article is distributed under the terms of the Creative Commons Attribution 4.0 International License (http://creativecommons.org/licenses/by/4.0/), which permits unrestricted use, distribution, and reproduction in any medium, provided you give appropriate credit to the original author(s) and the source, provide a link to the Creative Commons license, and indicate if changes were made. 
income level of those involved. Among the ageing population in China, the majority (it is estimated to be two thirds) of older people live in rural areas where many state welfare provisions are limited (Ye and He 2008). The position of the older people in rural areas is complicated by the fact that, since the 1990s, there has been a large-scale migration of younger workers from rural to urban areas and this has geographically separated many adult children from their ageing parents.

The Chinese rural-urban distinction is not simply a geographical issue; it is also a systemic one (Yan 2003). A household registration system - the Hukou-was introduced in 1958 and requires every Chinese citizen to be registered at birth with the local authorities as either an urban or a rural householder, and this divides the entire population into two different kinds of subject (Zhang 2001). The operation of the Hukou has deprived rural residents of many rights, including state pension and various welfare provisions that urban residents are entitled to and so rural residents have had little choice but to continue with a long established system of informal familial support (Lee and Xiao 1998).

Since the 1980s, China has adopted an approach to socialist development centred on economic liberalisation; collective farming has been displaced by a return to family farming, markets relaxed and government restrictions on rural-urban migration reduced. As a result, one of the largest migrations in human history has ensued, with an estimated 160 million people now classified as rural-urban migrants (Cai et al. 2012). Yet, despite moving to an urban area, the Hukou continues to restrict the migrants' access to resources and benefits in the cities. This lack of state welfare support, combined with an institutional discrimination against rural migrants, has created particular challenges for rural families in the context of rural-urban migration.

\section{Changing intergenerational support in rural families}

The impact of the rapidly ageing population and rural to urban migration on the old age support system in rural China is attracting unprecedented scholarly attention. This existing scholarship largely falls into three areas: the impact upon health and wellbeing of staybehind parents, how the structure of intergenerational support changes after migration and the gender division of intergenerational support for older people in rural families.

With respect to the impact of migration upon health and wellbeing of stay-behind parents, Zhang et al. (2005) found that household support and emotional support were effective in reducing mortality when delivered at closer proximity, implying that geographic distance has a negative impact upon the delivery of old age support (also see Cong and Silverstein 2011). With respect to the changes in the structure of intergenerational support after migration, Guo et al. (2009) found that support from outmigration, adult children became parent-need oriented; that is, parents in greater financial and instrumental need were associated with higher probability of receiving support. Luo and Zhan (2012) found that after adult children migrated, parents adjusted traditional expectations of filial piety and confined old age care to financial support. Cong and Silverstein (2011) found financial support (enhanced by migration) could have positive effects on financial security and the welfare of parental generations, to some degree offsetting the disadvantage of living at a distance. Going beyond unidirectional support flows from the migrant to their stay-behind family, Cong and Silverstein (2012) adopted a gendered extended family perspective to examine how older parents' 
involvement in grandchild care affected adult children's support for older parents, finding a two-way transfer between generations in the context of migration.

With respect to the gender division of intergenerational support for older people in rural families, the division between sons and daughters is a reflection of two interrelated social-cultural features (see Song et al. 2012; Cong and Silverstein 2012). In accordance with overarching filial norms, male heirs and their wives should be the primary providers of support for parents in old age while married daughters are obligated to provide support to their in-laws rather than their own parents (Lee and Xiao 1998). A gendered pattern of migration has complicated this model; that is, while both single women and men migrate to cities for work, after marriage, a man will generally return to migration labour while a woman will not (Fan 2003). Where migration is more established, however, a trend is emerging in some regions that once childbearing has been completed, mothers also migrate leaving the children behind with their grandparents. Studies of this group found that in the absence of sons, stay-behind daughters in rural areas are playing an increased role supporting their own parents (Xu 2001; Ye and He 2008; Song et al. 2012; Cong and Silverstein 2012). Nevertheless, while daughters play a more active role in their parents' support network, parents still name sons to be the preferred support providers (Cong and Silverstein 2014; Luo and Zhan 2012).

There are several limitations with existing scholarship: first, it is largely located in a framework of either a unidirectional transfer from migrants to stay behind kin or a twoway intergenerational transfer between adult children and older parents. The multidimensionality of the old age support system, including intra-generational dynamics, has been largely overlooked. Second, based upon an implicit assumption of migration as a momentous event, it has placed great emphasis on identifying the positive or negative impact of geographical separation with insufficient attention to revealing 'situational' factors mediating the impact. Third, existing scholarship is predominately concerned with the structure and function of support; this has been achieved at the expense of the processes and quality of support. This limitation is partly related to the fact that the majority of existing studies on rural ageing and intergenerational support draw upon survey data ${ }^{1}$ and this is generally collected from only one member of the older generation in a study unit. While survey data can quantify intergenerational transfer, existing studies inferred interactions between parents and adult children instead of examining the process directly and so this approach does not capture the subtleties and complexities within a family. Finally, existing studies generally draw upon data from a single region; given the scale and diversity of rural China, variances in intergenerational support between different regions have been completely overlooked. Given the limitations of the existing scholarship, rapidly ageing population and large scale rural-urban migration in China, there is an urgent need to seek a new analytical approach that captures both wider advances in academic research and the changing make-up of rural family life in the context of migration.

\section{Migration and care}

Many global policymakers see migration as a vehicle for potential economic growth; however, it also presents major societal challenges. In response to this, there is a growing global scholarship on the migration-care interface. One strand of this literature has examined transnational mothering in the context of 'global care chains' (see Hochschild 
2000) and drawn attention to phenomena such as 'care drain' and 'care replacement' (see Lutz and Palenga-Möllenbeck 2012). This focuses upon the unidirectional care flows from the migrant to their stay-behind family and is framed within the context of commodified female domestic labour flows from the global south to the global north. Another strand of research has drawn on a broader definition of transnational families to include a wider range of multidirectional, intergenerational care relationships (see Baldassar et al. 2007). This research tends to challenge the prevailing assumption that geographical distance negatively affects family caregiving by emphasizing the 'portability of care' (Hoang and Brenda 2012).

Following the broader definition of transnational families, Baldassar and Merla (2013) have developed a conceptual framework-'care circulation'-in order to unite the studies of migration and caregiving. They define 'care circulation' as 'the reciprocal, multidirectional and asymmetrical exchange of care that fluctuates over the life-course within transnational family networks subject to the political, economic, cultural and social contexts of both sending and receiving societies' (2013:22). This concept reiterates that mobility and absence are normal features of modern family life, as opposed to the common perception that families are formed by members who live in close proximity (Baldassar and Merla 2013). While Baldassar and Merla focused on transnational families, given that the Hukou restrictions have a similar function as the immigration constraint on transnational families, their framework is applicable to Chinese internal migration. There are a number of reasons why the framework is a particularly effective method for informing the analysis of the Chinese data.

First, a broader definition of care assists in understanding the interactions between family members in different geographical locations. Baldassar and Merla follow Finch (1989) and define family care involving the following: financial and material support (including cash remittances or goods such as food, clothing, and paying household and other bills such as medical care); practical support (exchanging advice and assisting with tasks); emotional and moral support (aimed at improving psychological wellbeing); personal care (feeding and bathing); and accommodation (providing shelter and security). This multidimensional lens enables distinctions to be made between proximate caring practices that require physical co-presence; caring practices that can be exchanged at a distance through the use of communication technologies and proxy caring practices involving the coordination of support provided by others (Baldassar et al. 2014).

Second, governed by 'norms of generalized reciprocity', care is 'given and returned at different times and to varying degrees across the life course'; thus, care should be 'circulating among family members over time as well as distance' (Baldassar and Merla 2013:7). This feature of care helps move beyond the current literature on old age support in rural China that is embedded in either a unidirectional or a two-way intergenerational transfer and necessitates an examination of intra-generational and intergenerational dynamics. Further, the temporal component draws attention to the ways in which care needs evolve over the life course and how different generations are situated in the spectrum of dependency and independency as care providers and recipients. Indeed, migration itself has a temporal dimension and so caregiving and carereceiving roles, as well as caregiving arrangements, vary over the migration cycle, as well as over the life course. 
Third, the care circulation framework emphasizes that the quality of the relationship is more important in the efficacy of care exchange than the mode and form of caregiving (Baldassar et al. 2014). This highlights the need to look beyond the task and pay attention to the quality of care. Western scholarship on care has drawn attention to two different but interrelated dimensions of care in the English language: 'caring for' and 'caring about'. Caring for is an activity state, often associated with serving needs, specific tasks and obligations while caring about someone is a feeling state, linked with affection, affinity and emotion (Thomas 1993; Ungerson 1990). Studies in western countries have shown that 'effective' care requires 'caring about' emotions while some family care can be provided in an instrumental and calculative spirit (Bowlby, et al. 2010). In the Chinese language, there is not an encompassing word like 'care' but a number of terms exist to describe caring relationships. The terms, zhaogu or zhaoliao, are the closest equivalent of 'caring for' and guanxin is the closest equivalent of 'caring about'. Since zhaogu/zhaoliao ${ }^{2}$ are generally used when collecting survey/interview data, the existing literature on ageing in rural China can inform us about the frequency and contents of caring practices but little is known about 'caring about' and the effects/ quality of care.

Finally, Baldassar and Merla (2013:12) highlight the importance of 'taking into account the structurally diverse, asymmetrical, situated and gendered ways in which care may circulate within transnational family networks'. This is illuminating in two respects: as Chinese families are traditionally organized according to a hierarchy of gender, age and generation, this framework alerts us to the need to examine how the intersection of gender and generation might shape the exchange of care between family members in rural China. Further, the emphasis upon 'situated' contexts necessitates an investigation of local sociality in impacting the ways inequalities of care circulation are produced. For example, different migration trajectories in different regions have been identified (Fan 2007), but how these different paths affect the old age support system remains unexplored.

This article is the first to apply the 'care circulation' analytical framework to examine the processes of care for old people in rural China, an area which has hitherto been predominantly located in a quantitatively based intergenerational transfer framework. Through the case study of rural China, this article also hopes to add to global knowledge of ageing, migration and family from a Chinese perspective. For thousands of years, filial piety was the defining principle of relations between adult children and older parents in China. The key features of filial piety were a total submission of the will of adult children to that of senior generations. Adult children were therefore obliged to provide all-round support to their parents, and it was a patrilineal obligation because the patrilocal custom placed married daughters on the filial map of their in-laws.

As a consequence of the twentieth century's political and socio-economic transformations, the nature of filial obligation has changed; filial piety has morphed into a filial support based upon 'mutual need, mutual gratitude and mutual support for two-way exchange of support and care' (Croll 2008:110). Under this new 'intergenerational contract' (Croll 2008), reciprocity has become the key principle in maintaining a two-way exchange of support. In spite of this, contemporary intergenerational relations in China remain culturally defined by a sense of obligation that may or may not mix with emotions of 'love' and the qualitative history of their relationships. By 
grounding analysis in a local-cultural sociality, this article reveals the Chinese moral ethics and rural material reality that bind people within networks of family duty and reciprocity act as a 'pump' (Tronto 2011) in the Chinese care circulation system.

\section{Methodology}

The majority of existing studies on intergenerational relations in rural China are statistical surveys. Although these studies may map out a trend, this is often to the detriment of examining in more depth the complexities and dynamics of lived experiences, tensions, strategies and expectations of the people who have experienced social change. In particular, policy formulation for ageing in the Global South requires knowledge of the internal dynamics of communities, neighbourhoods, kin networks and family relations and requires qualitative research to bring up the silences within the arena of dayto-day living to the surface' (Risseeuw, 2001:28-29). A qualitative methodology has been adopted here to capture the micro-level processes that constructed people's experiences. Research shows the value of life histories in capturing lived experiences and personal accounts of human agency (Wengraf et al. 2002) especially in the context of migration. Furthermore, life history provides the overlap in the chronology between family members and is particularly important in studying family relationships. As most people live most of their lives in families, life history interviewing is an effective approach for gaining in-depth insight into changing family relationships and relevant strategies.

Using Chinese academics as local contacts, I was introduced to two villages in rural China (one in Shandong province, village 1, and one in Hunan province, village 2) and lived in each village for 2 months, respectively, during 2011. Purposive non-random sampling techniques were used to recruit families to the study (Mason 2002) ensuring that a broadly representative spread of ages, gender, social hierarchies and family sizes were included. In total, 17 families took part in the project and 60 individual, private, interviews were conducted across at least two (and sometimes three) generations in each family with both male and female family members. The representativeness of a small-scale in-depth study in the two villages is inevitably limited compared with the scale and diversity of China. However, as indicated in the 'Findings' section, this study found similar processes of general intergenerational trend as quantitative studies in other regions, reflecting the commonalities of the villages experiencing a high proportion of migration and strengthening the transferability of the findings to the understanding of rural families in the context of migration.

Each interviewee was asked to recall his/her childhood first and then encouraged to take the lead. If not covered during the natural course of the ensuing conversation, specific questions relating to relationships with family members were asked. All interviews except one were tape recorded and fully transcribed. A thematic analysis was applied to each transcript to identify common themes that emerged from different transcripts in each generation. A further in-depth analysis on intergenerational relations was also carried out for each household.

In both villages, a high proportion of the population was over 60 years old (13\%-similar to the national average) and a high proportion of households had experienced migration (70\%). In the Shandong village, there was no state pension provision; by contrast, the Hunan village had been included in a national pilot pension scheme 
(covering $10 \%$ of the villages in China) which entitled all inhabitants to a monthly state pension of 55 Yuan (c. £5) on reaching 60 years old. Entitlement to the pension was based upon all adult family members contributing to the scheme.

Both sets of villagers were covered by state medical insurance. However, like the rest of rural China, the level of cover was grossly insufficient, that is, state reimbursement only related to hospitalization and so villagers could not use their contribution to offset the cost of medicine (which was a major form of medical treatment for them). With ineffective state support, it was the family unit that villagers could turn to when they needed help. Informal familial support formed the major basis of welfare provision in both villages.

In village 1 , since the early 1990s, young male villagers had started to migrate to the cities to work (mainly Beijing and other provincial cities in Northern China) but the number was relatively small. Having seen the early pioneers earn considerably inflated wages, others followed and migration increased markedly from 2000 onwards. The gender composition of migrants aged between 16 and 25 was balanced. For this cohort, young men and women usually migrated to work in a factory after completing/dropping out of school. However, after returning to the village to marry, the majority of husbands continued to migrate while wives stayed behind in the village (although a small number of couples migrated together). Therefore, the people who formed the majority of village residents day-to-day were older people, married women and grandchildren. The older generation lived on their own, the stayed-behind daughter-in-law and/or married daughters actively engaged in non-agricultural work in nearby towns but would return to the village everyday and so were on call if needed. Grandchildren lived with their own mothers but during the day when their mothers were at work, were handed over to older generation.

Being close to Guangdong, one of the earliest economic development zones in China, village 2 had a longer history of outward migration; from the early 1980s, young men first went out to work on construction sites after dropping out of school. Most of them returned to the village to get married, and then, their wives stayed behind to look after their young children. From the 1990s, young women had started to join young men with most working in the factories of Guangdong. For married women, when their children reached school age, they followed their husband to the cities for work (generally either supporting their husband by street vending or working in factories). As a result, since 2000, unlike village 1 , the village 2 households were mostly formed of older people and their grandchildren.

To examine deeper, the complexities of lived experiences, strategies, expectations and preferences within a household setting and in particular the relational dynamics between different generations, this article discusses and analyses two family case studies ${ }^{3}$ in-depth while supplementing discussions with examples from other interviewees in the same village. Names have been altered to maintain the anonymity of the interviewees.

\section{Findings}

\section{Family case study 1}

The Wang family lived in a multigenerational household in village 1. Mother Wang was born in 1932, had only one (older) brother who had been sent to school and later became a teacher; however, in keeping with gender norms of the time, she had not 
received an education. Instead, Mother Wang was kept at home and taught how to spin cotton and weave cloth. In 1951, as a result of an arranged marriage, she was married into village 1,4 km away from her natal village. A few years after her marriage, collectivization of agriculture started so she began to work in the fields along with her husband to earn work points. She had three sons and one daughter. She wanted her sons to do well in education, but all dropped out of school as they did not want to study as well as help with farm work. Her daughter was sent to school for only 1 year. Her youngest son died of an acute illness at the age of 21, while the other two sons were married within the village and each had three children and recently a grandson for each family. Her daughter was married into a nearby village and had two children. Mother Wang, the elder son's wife, grandson (elder son's son) and grandson's wife were interviewed individually.

In 2007, Mother Wang broke her leg, was subsequently diagnosed as being hemiplegic due to cerebral thrombosis, and became bed-ridden and her husband became her everyday carer. At this point, Mother and Father Wang gave up their field to their sons' families to tend. In return, the sons provided them with grain and other provisions such as coal. To pay for her medical treatment, Mother Wang and her husband used up their life savings of 2000 yuan and the remaining bill was divided equally among the two sons' families.

In 2009, Mother Wang's husband suddenly died of stomach cancer and her daughter moved back home and cared for her for 5 months. After this, her daughter and two sons' families formed a caring rotation: each adult child cared for Mother Wang every 5 days. The caring tasks involved sending meals, dressing her, helping her to the toilet and sleeping in her house at night (bathing and washing dirty clothes and bed sheets were left to the daughter's rotation). Mother Wang lived on the food and cash provided by her two sons' families. Her daughter and her grandchildren often gave her gifts (such as clothes and food) and money during significant Chinese festivals.

The obligation to care for Mother Wang had become an issue for the elder son's family because the elder son migrated away in 2007 and only returned to the village twice a year. The reason to migrate was related to his life course; he was responsible for the financial situation of the young as well as fulfilling a filial duty towards the old. The wife of the elder son (aged 57) recalled: 'why did he migrate? Previously we were doing some street vending in the village in addition to farm work. Then I said to him: "street vending won't work, our second daughter is still in education, our son needs a wife and we need to provide for the older generation. The income from street vending won't be enough. Street vending can only earn us some pocket money. Don't do street vending any more. Go out to the city for work"'. Persuaded by his wife, the elder son joined his neighbours and found a job on a construction site in a city in another province. In the first year, he did not bring any income home as his boss withheld payment and then ran away. In the second and third year, he managed to bring home on average 11,000 yuan a year, much higher than their income from farming (c. 5000 yuan a year).

With the migration income, the family managed to find his son (that is, Mother Wang's grandson) a wife. This process involved the biggest outlay of their life; paying a bride price of 10,000 yuan according to local custom plus wedding expenses, and on top of this, they needed to build a separate marital house for the young couple. When his daughter-in-law gave birth to a son soon after the marriage; they paid all the 
expenses (c. 6000 yuan) associated with the childbirth and celebrations, which meant they were in considerable debt at the time of interview. In order to pay off the debt, the elder son planned to continue migration labour.

In addition to the elder son, Mother Wang's grandson and granddaughter-in-law were also migrants prior to their child's birth. Given the income gap between farm work and migration labour, young people usually followed the migration trend. As Grandson Wang (aged 22) put it, 'I hated going to school so I went to the city with my neighbours in the village, with a total of over 30 people'. However, he spent most of his wages and did not manage to save much money prior to his marriage. He planned to continue to undertake migration labour while his wife stayed behind in the village to look after their child. His wife supported this decision: 'he has the idea but hasn't found a job yet. I would rather let him go outside for work than stay idle at home. If he stays in the village, there won't be much cash income'. When asked if his migration would affect their feelings towards each other, she replied positively with a 'no' and commented 'as long as we have money, his migration won't affect our feelings'.

Migration was a necessity, lifting rural families out of a subsistence livelihood dependent upon agriculture; however, it put a strain upon those who stayed behind. When asked how she and her mother-in-law coped when both her husband and fatherin-law migrated for work, Mother Wang's granddaughter-in-law admitted: 'last year when both of them had gone, my mother-in-law and I were absolutely swamped. Especially during the rotation period in which we were required to look after our bedbound grandmother-in-law, we could hardly manage. ... I had no time to eat. If we cooked meals at home, my mother-in-law had to send the meal to the grandmother-inlaw and come back when she finished. As I was looking after the baby, I didn't have time to eat. When my mother-in-law came back, I then took turns to eat my meal, which was already cold. Without the baby, we could have managed but adding the baby, it was really difficult'. Her role was mainly to look after the baby while her mother-in-law was the main carer for Mother Wang and the primary farmer of the crops on their over one acre of allocated family land.

Faced with her elder son's migration, Mother Wang did not like it but did not intervene given the economic circumstance of the elder son's family. Mother Wang recalled: I said to him, "you can go but you must have arranged someone to look after me. I can't handle it on my own". After he left, his wife slept in my house during the night. I can't really forbid him to go out to make money. I did ask him, since he is nearly 60 years old, why bother migrating to work? But he replied, "we are still owning others' money. Hopefully I can work for another year to pay off the debt then I won't go out any more". Our children's life is not easy'. Her second son's economic condition was not much better, but his family was not in debt and so he stayed in the village taking on odd paid employment in a nearby town enterprise in addition to tending crops. Mother Wang spoke of the second son fondly: 'my second son never left home for migration. He said to me, "Mum, my elder brother has gone, if I go too, you cannot get hold of any son"'. Reflecting on the care she received from her children, Mother Wang did not complain about the support provided by her children but became upset and emotional by her dependency upon them: 'I get angry easily, not about others but with myself. I was angry about the fact that I couldn't move. My sons cannot stay with me all the time. When they are busy, I cannot keep them otherwise how can they work 
and make a living? ... To be frank, I don't want them to leave me alone. When they leave, I cry. I don't cry in front of the children, as I am well fed and provided for. What else do I cry for? ... I feel very upset and sometimes cry for several hours. But crying is no use. Nothing is helpful unless I die. I am willing to die. Tell me, what do I live for?'

\section{Family case study 2}

The Chen's family was a skipped generation family in village 2. Father Chen, who was born in 1931, only studied in school for 3 years because his parents were very poor. His first wife died shortly after giving birth to their only daughter. Mother Chen was his second wife; she was born in 1938 in another village and like Mother Wang she did not receive any education. Being the eldest child, she helped to bring up her siblings after her mother died at the age of 40. After their marriage in 1953, Father Chen worked in the village committee as an officer and Mother Chen took on both domestic duties and farm work; indeed, Father Chen acknowledged that his wife was more capable than a man. Father Chen retired early due to ill health in 1984 without a state pension as only village officers appointed in later years received a pension.

Father Chen and Mother Chen had two daughters and two sons together. The elder son (aged 46) and his wife migrated to Guangdong province, setting up a shoe shop, and had three daughters and one son. The second son joined the army after middle school and became a public servant in the province of Guangdong and then settled there; he got married in his late 30s and had only recently had a baby daughter. The eldest daughter of Father Chen (from his first marriage) lived in a nearby town ( $40 \mathrm{~min}$ by bus) where her children studied at the local middle school. The second daughter lived in the nearby town and made a living from street vending; the youngest daughter lived in a nearby city (90 min by coach) and owned a small fruit shop. Father Chen and Mother Chen felt strongly that education would enable people born in the countryside to lead a better life. However, with the exception of their youngest son who had eventually joined a military academy, all of Father Chen's children only finished junior middle school (approximately 9 years of education).

Father Chen's elder son migrated away in 1989, and the son's wife stayed at home while their children were still young. By the late 1990s, the daughter-in-law had followed her husband to the city, and for the next decade, Father Chen and Mother Chen looked after their four grandchildren by the elder son. By 2011, the older granddaughter worked as an administrator after leaving university; the second granddaughter had joined her father in the Guangdong shoe shop; the youngest granddaughter was in her final year of boarding school preparing for her college entrance exam (and visited Father Chen and Mother Chen over the weekend) and the grandson now studied in a college in the provincial capital ( 5 h by coach from the village). Father Chen, Mother Chen, elder son and elder son's oldest daughter were interviewed individually.

After retirement, Father Chen was not in a good health (suffering from chronic bronchitis and coronary heart disease), so his wife continued to be mainly responsible for the fields. Father Chen helped her occasionally by cutting grass and cooking meals at 
home. At their children's insistence, they gave up working in the paddy fields in 2007, but Mother Chen still grew vegetables and orange trees and raised chicken and fish for their own consumption as well as earning some cash income. The two sons regularly sent money home towards their living expenses. Their daughters and working grandchildren sent them gifts and money during Chinese festivals.

In 2010, Father Chen became hospitalized for 1 month. Mother Chen told how the whole family supported him:

Q: Who looked after your husband during that month?

A: I took care of him. Sometimes, my daughters came to visit us. I handled it myself and didn't want to use their time. As they didn't have time during the day, they usually visited us after work. My youngest daughter was especially helpful as she lives close to the city hospital. Since it was expensive to have hospital meals, she sent meals to us most of the time.

Q: So who was washing clothes for him in the hospital?

A: It was me, too. I handled all these duties myself.

Q: So did your sons and daughters-in-law come to visit him?

A: My sons and daughters-in-law didn't come back because they were too far from here. They just sent money back and asked their sisters to take care of us. Money can solve everything. As long as they sent the money back, all is okay. I am still here so can look after him. If I am not here, I am certain that they will come back to look after him in hospital.

Father Chen's hospitalization cost 20,000 yuan in medical fees. His two sons paid the bill, but his younger son contributed more since he felt he was better off (earning 10,000 yuan a month) while his brother had a heavier financial burden due to his children's education costs.

Speaking of his children's migration, Father Chen commented: 'when the younger generation earn money in the cities, old people like us will have a better life at home'. When I asked about the older generation's emotional needs, he commented 'we have no choice. If my sons stay behind, we haven't got enough money. It's fine if we have enough to eat and to spend. What else do we feel lonely about?' While this was how he felt now, when reflecting upon the skip generation arrangement he admitted that it was a very difficult time: 'after my elder son and his wife both went, their four kids were all 
left to us. Emotionally it was fine, but it was a big financial burden for us because there were all the children's living expenses plus the costs associated with breaking the family planning policy. I had been a village officer but my son broke the state policy by having three daughters and another boy. The fine was a large sum. I had no choice. The Family Planning Officers came to our house to take stuff away. I said to them, "take whatever you like". Everyone should be punished if breaking the policy including the cadres'.

It was only in the last 4 years that life began to improve; the four grandchildren left home one by one and their children had also managed to save up some money. Mother Chen recalled, 'our children said, "you have worked so hard, now we have some money, please do not work in the fields any more"'. When asked about future old age care, Father Chen commented: 'if my wife is capable, I'd prefer her to look after me. If she can't, I will ask my children to come back'. His confidence in his children came from the belief that 'if you take care of your children well, they will look after you well when you are old'. By contrast, as Mother Chen, who was 7 years younger than Father Chen, predicted being alone in old age, pointing to the discrepancy between her children's availability in the village to care and the need for them to migrate, and considered hiring someone to care for her in future with money sent by her children.

\section{Discussion}

\section{Care circulation}

While the Wang and Chen family histories appear very different from each other, they were a product of their own local circumstance and not atypical in their respective village. In village 1, the migration trend really started from the millennium onwards and so men and younger unmarried women migrated to the cities. By contract, village 2 had a much longer history of migration starting from the late 1980s, and men and married women were both actively engaged in migration and so the skipped generation (i.e. older people and grandchildren) was a common form of living arrangement.

The experiences of the Wang and Chen families indicate that familial care circulates between different members, at different locations, over the life course. In the Wang family, at the time of interview, the network of care for Mother Wang was mainly formed of the elder son, the elder son's wife when the elder son was away in the city, the younger son and Mother Wang's own daughter. Mother Wang remained in her own accommodation but the two sons' families provided material support including food and some cash for day-to-day expenditure and medicines; everyone in the network provided practical support during their rotation; the younger son was the main source of emotional support; while Mother Wang's daughter was her main source of personal care. As Wang's accommodation did not have a phone or other electronic communication facilities, the caring mostly involved proximate caring practices. When away, the migrating elder son sometimes performed proxy care by phoning his wife or to check on things during their family's rotation.

The care network for Mother Wang was relatively recent, having been introduced following her husband's sudden death in 2009. Prior to this, Father Wang was the primary source of emotional, practical and personal care with the two sons' providing some material support and all of Mother Wang's children providing emotional support when 
visiting her. Mother Wang commented 'when my husband was alive, I didn't need any of my children here. Everything was done by him'. Before Mother Wang became bedridden, she and her husband worked on their land and lived a fairly independent life. During the 1990s, Mother Wang's two sons' families were the care recipients in the familial care circulation as she provided childcare to various grandchildren (mainly sons' families) as they grew up.

In the Chen family, the network of care for Father Chen consisted of his two sons, three daughters and his wife. In the years immediately after his retirement, Father Chen helped with cooking and some chores. However, as his health deteriorated, Mother Chen provided practical support, emotional support and personal care to Father Chen in addition to managing the household. Material support was mainly provided by the two sons who sent frequent remittances; some emotional support was also provided by the sons when they called home and three daughters when they visited or called home. During Father Chen's hospitalization, all family members worked together; the two sons performed proxy care (by asking their sisters to visit) and sent cash to pay medical bills. The three sisters visited the hospital to varying degrees, providing emotional support. The practical support and personal care were mainly carried out by Mother Chen.

The Chen's family history revealed that they had only started to receive remittances in recent years when the elder son's life improved and the second son settled in a good job. Prior to that, rather than being care recipients, Father Chen and Mother Chen provided material support to both sons (for example, paying the fine when the elder son breached the one-child policy and supporting the younger son's military academy studies). More importantly, the elder son's four children had stayed with them for almost 10 years while the elder son and his wife were migrating in the city. The care intensity of grandparenting, shaped by the number of children in all-round care and the lengthy period involved, put considerable strain upon Mother Chen and Father Chen.

The circularity of care illuminates intra-generational dynamics and points to an important old age care pattern that is overlooked in studies of intergenerational transfer, that is, care from spouse. In both families, spousal care was the first choice for both practical support and personal care and this was confirmed by other families in each village. As Father Zheng (in village 1) put it, 'how one's children treat parents are not as good as how a couple treat each other. Being looked after by one's spouse is the best'. Mother Xu (in village 2) and her husband looked after each other but she dreaded life alone: 'I don't know which one of us will die first; anyway, the one who will die first is the luckiest'. There are two drivers of this preference: first, practical support and personal care require an intimate knowledge of each other (Gabb 2008) and the relation among the couple is often considered the closest because of shared life experiences together; second, older interviewees were aware of other mediating factors that would impact the ways in which their adult children delivered old age care.

\section{Mediated impact}

It is difficult to generalize whether migration has a positive or negative impact on stayed-behind older parents' later life as the intergenerational dynamics are far more complicated and contextualized than a simple verdict can capture. However, four situational factors have been identified: (i) employment status of the migrating children, (ii) 
the temporality of migration, (iii) family life cycle of the migrating children and (iv) the family relations between the older generation and adult child generation, all of which have played a mediating role in managing the impact of geographical separation upon old age support system.

Comparing the employment status, the two sons of Family Chen (younger being a civil servant and elder being a small shoe shop owner) were in a much better financial position than the two sons of Family Wang (one being construction worker and one being a farmer). With greater financial resources, the Chen's 'capacity to care ${ }^{4}$ ' (Baldassar and Merla 2013) was much stronger than the Wang family. As a consequence, Father Chen was sent to a municipal level hospital, which is generally considered to have higher quality medical provision compared to town-level hospitals, while Father Wang made do with a local folk recipe to deal with his stomach cancer.

It is important to note that the public servant career of the younger Chen's son was very unusual as most rural migrants end up in low-paid manual jobs. However, the migration history of the Chen's elder son was not uncommon and demonstrated the temporality of migration, in particular the start time in an individual's migration was an important factor. The Chen's elder son, like the Wang's elder son, took on his first job on a construction site and worked there for over 8 years. But unlike the Wang's elder son, he first migrated in his 20s; and so with the money saved from working on a construction site, he was able to set up a small shoe stall which gradually turned it into a shoe shop 10 years later.

The 'family life cycle' (Baldassar and Merla 2013) of the migrating children played a role in determining their capacity to care. Mother Chen and Father Chen's narrative confirmed that their life had only improved in the last few years, partly because two of the four children of the elder son had started working and the wealth accumulated made it possible for the elder son to send money towards their living and medical expenses. Before 2007, the elder son was not in a position to send money to his parents as he needed to pay for the education of his four children (he confessed 'the biggest expenses were the children's education costs'). During Father Chen's hospitalization in 2010, the three daughters were relatively close geographically, but because their own children were in high school (including one preparing for a university entrance exam), they did not have the time to be the main providers of practical and personal care. Similarly, when Father Wang died, the elder son was in a difficult family life stage with the responsibility to provide for his second daughter's education, finding a wife for his son, and caring for his mother-this put a huge financial strain upon his family.

The relationship between the adult generation and their parents played a critical role in old age support. Mother Wang considered her younger son to be most caring and when asked whom she wanted to look after her, replied: 'my younger son. He visited me far more frequently. My older son's house is slightly further away (15 minutes by foot) so I said to my older son: 'please stay here, once you are gone, I don't know when you will be back'. Two hours at home might go quickly for him but for me it is hard as I might go to toilet at any time. By contrast, my younger son came to visit me at least 20 times a day. He lived closer ( 5 minutes by foot) so visited me almost every half an hour'. As Mother Wang was bed ridden and did not have a phone in her house, other's company was appreciated by her.

Mother Wang's differentiated relationship with the two sons was further revealed in the interview with the elder son's wife. The daughter-in-law held a grudge against 
Mother Wang whom she felt favoured the younger son's family and had not divided the family estate equally between the sons. When the elder son migrated, his wife carried out her care duties on the agreed rotation; however, her motivation was to avoid any village gossip that she was an unfilial daughter-in-law; that is, there was no 'caring about' in her relationship with Mother Wang. In fact, she revealed that she did not wish her mother-in-law to get better but wanted her to continue suffering even though this meant she would need to continue performing the tiring care work.

In the Chen family, relationships were less strained but Mother Chen's narrative did reveal that the two older daughters were the less close. Reflected in the caring relationship, the two older daughters called home less often than the younger daughter and two sons; when Father Chen became hospitalized, the younger daughter sent meals every day while the older daughters visited their father only a couple of times during the entire time he was in the hospital. Caring for activity does not necessarily entail caring about but having a caring about component will improve caring for activities. The quality of care was represented by the sensitivity of Mother Wang's younger son and Father Chen's younger daughter towards their parents' care needs.

\section{Gendered and generational consequence-local variations}

Traditionally, Chinese families are structured hierarchically based upon age, generation and gender. However, the communist revolution in the mid-twentieth century launched various campaigns to reform the family with the immediate aim of stamping out the power of family elders in order to reorient citizens' loyalty to the state (Davin 1976). While these campaigns (for example, collectivization and commune) somewhat undercut the power and authority of family elders, material necessity and the immobility of labour (reinforced by the household registration scheme-see the 'Background' section) often required a strengthening of family ties in rural Maoist China (Davis and Harrell 1993). Ironically, it was the indirect impact of post-Mao government policies, which encouraged urban-rural income inequality, increased the economic power of the younger generation, and so lead to a decline of parental power (Jing 2004; Miller 2004; Yan 2003) and reshaped intergenerational dynamics. As a result, there has been a shift from traditional filial piety, characterized by a subordination of the young to the will and welfare of parents and grandparents, to filial care based upon 'mutual need, mutual gratitude and mutual support' (Croll 2008:110). Due to continuing gendered division of labour in rural families, this changing intergenerational contract has gendered and generational consequences, the impact of which needs to be assessed within locally situated contexts.

In any couple with adult children who migrated to the cities from a young age (20s), it was the woman of the older generation who took on the increased care responsibilities. However, the different migration trajectories of the villages meant the cohort of women who endured the greatest burden of care was different. In village 1, migration had only really got going from the millennium onwards and, due to the relatively generous availability of land in the village, ${ }^{5}$ the gendered pattern had meant that men and single unmarried women migrated while older and married women remained behind. Therefore, it was the middle generation, women of the 50-60 cohort that took on the majority of care responsibilities (as the Mother Wang's daughter-in-law put it, 'ahead has the old and behind has the young'). While her son's wife stayed behind to look after 
the newborn baby, Mother Wang's daughter-in-law had to tend her own land, and that of her son's family, in addition to looking after Mother Wang on rotation. If her son's wife followed her husband to the city in a few years, Mother Wang's daughter-in-law would be expected to take on grandparenting duties in addition to the existing farm work and care responsibility of her mother-in-law.

Women of the 50-60 cohort in particular were burdened with the responsibility to care for their in-laws as well as own parents-there was an increased role for daughters in parents' support network primarily because of their brother's migration (see Cong and Silverstein 2012; Xu 2001). For example, the only daughter of Mother Wang took a share in the care rotation and was responsible for washing all the dirty clothes and bed sheets of Mother Wang. Because of her brothers' migration, the elder son's wife also cared for her own mother who suffered from dementia and died 2 years previously. Reflecting upon her caring responsibilities, the elder son's wife commented: 'I feel that I have been like an old ox all my life, pulled here and there and sometimes couldn't breathe under the pressure'.

Village 2 had a more established history of migration than village 1 , and the availability of land for farming was more limited-both factors meant that men and married women were both actively engaged in migration. The gendered division of labour and generational inequalities produced a differentiated impact of migration with older women being disproportionately affected. Female parents in particular facilitated the migration of their children through the feminization of farming and childcare. It was the women in cohort $70-80^{6}$ that were disproportionately affected by their adult children's migration. Like her village contemporaries, Mother Chen's life history involved agricultural work, bringing up her own children, bringing up her grandchildren and caring for her unwell husband. Although Mother Chen did not experience the double burden of caring for an in-law as well as her own parents, like Mother Wang's elder daughter-in-law, her ageing experience was reshaped by adult children's migration.

\section{Conclusion}

Drawing upon qualitative data on family life in rural households in China and applying the concept of care circulation, this article has examined the processes of care for old people in the context of rural to urban migration, an area which has been predominantly located in a quantitatively based intergenerational transfer framework. Going beyond a unidirectional flow or two-way transfer, the multidirectional and asymmetrical exchanges of caregiving and care-receiving has been revealed: care circulates between different members, in different locations, to differing degrees, over the life course. This circulation framework also enables an investigation of intra-generational dynamics as well as intergenerational relations. For example, in terms of practical support and personal care, there appears to be a hierarchy of preference with spouse at the apex, followed by adult children, and daughters-in-law at the nadir.

In contrast with existing scholarship on ageing in rural China, which tends to provide a positive/negative verdict, this article has adopted a more nuanced analysis to identify the situational factors that mediated the impact of migration upon old age care. A good material condition of the migrant children would enhance their care capacity while economically worse off migrant households are stretched by their care responsibilities towards the old. The temporality of migration as well as the family life cycle of the 
migrants also positions migrating children and their parents differently in the dependency/independency spectrum. Younger migrants heavily relied upon grandparenting support provided by their stay-behind parents. Given that most migrants engaged in low-paid manual jobs, only in a much later stage of migration were they in a position to provide for their parents financially. Further, the relationship between adult children and old parents affected the quality of care delivered. If there was an intimate relationship, it did not change with the increasing geographic distance (see Liu 2016). But if the relationship was strained, there was no 'caring about' in the care activities even if residing in the same village. Exactly because of the differentiation between 'caring for' and 'caring about', there is an urgent need to pay more attention to the quality of care instead of simply identifying care provision in future research on rural ageing in China.

By highlighting the mediated factors in delivering intergenerational support, this article also points to the different roles played by the obligation to care and the capacity to care in the care circulation system. The moral ethics of filiality and rural material sociality owing to long-established urban-rural segregation tied people within interdependent networks of family obligation and reciprocity. The obligation to care served as the driver to the rural Chinese care circulation system. However, in order to materialize the obligation to care, the capacity to care served as the energy resource to make the care circulation system operate. If either is lacking, then the care circulation system is not sustainable. The dynamics between both aspects deserve further investigation in future global studies of the care circulation system.

Migration is a necessary means of lifting rural households out of subsistence farming and at the same time giving the younger generation an economic opportunity that the older generation was deprived. This new wider social context has reconditioned intergenerational dynamics; that is, the traditional hierarchical family authority structure is on the wane and yet the patriarchal structure and gendered division of labour in rural families remain. Due to the generational inequalities and the gendered construction of care work, stay-behind older women have been disproportionately affected by their adult children's migration. Their ageing experience has been reshaped by the feminization of farming and increasing care responsibilities as a result of the younger generation's migration. This gendered and generational impact has been assessed here in locally situated contexts; this article draws attention to the ways in which local migration trajectories interact with intergenerational dynamics to determine the cohort of women that endure the greatest burden of care.

\section{Endnotes}

${ }^{1}$ The exceptions are a few anthropological studies on old age support in rural China (Yan 2003; Zhang 2004; Miller 2004; Jing 2004). These studies shed lights upon the strategies and negotiations involved in intergenerational support between adult children and older generations; however, they were mostly conducted in the 1990s and largely remain set in a two-way intergenerational transfer framework.

${ }^{2}$ For example, in the reputable China Health and Retirement Longitudinal Study, undertaken by Beijing University, zhaoliao (caring for) was used in the questionnaire sections relating to the access and provision of care. 
${ }^{3}$ Each family is chosen because its arrangement of care for the older generation is representative of the pattern found among the households interviewed in their respective village.

${ }^{4 \prime}$ Capacity to care' is relevant in all settings, whether involving mobility or not, and refers to the 'physical and mental ability, opportunity and resources required to engage in caregiving' (Baldassar and Merla 2013:40).

${ }^{5}$ In village 1 , each person was allocated 0.2 acre by the village committee. In village 2 , each person was allocated 0.04 acre.

${ }^{6}$ Although a man would look after his wife (as in the Wang family), on most occasions, the wife provided care for her husband in old age given the extended longevity of women (and tendency for the man to be older in the relationship).

Competing interests

I declare that I have no competing interests.

\section{Acknowledgements}

This research was funded by the UK Economic and Social Research Council (grant number RES-000-22-4031). While this article represents my interpretation of the data, I would like to extend my thanks to Joanne Cook, the project coinvestigator. I am also grateful to Majella Kilkey for introducing the concept of care circulation to me and to Stevi Jackson and two anonymous referees for their constructive feedback during the review process.

Received: 25 January 2016 Accepted: 25 May 2016

Published online: 03 June 2016

\section{References}

Baldassar, L., C. Baldock, and R. Wilding. 2007. Families caring across borders: migration, aging and transnational caregiving. London: Palgrave.

Baldassar, L., and L. Merla (eds.). 2013. Transnational families, migration and the circulation of care: understanding mobility and absence in family life. London: Routledge.

Baldassar, L., M. Kilkey, L. Merla, and R. Wilding. 2014. Transnational families'. In Revised Blackwell Companion to the Sociology of Families, ed. J. Scott, J. Treas, and M. Richards.. Wiley Blackwell.

Bowlby, S., L. McKie, S. Gregory, and I. Macpherson. 2010. Interdependency and care over the lifecourse. London: Routledge.

Cai, F., J. O'Keefe Giles, P. O'Keefe, and D. Wang. 2012. The elderly and old age support in rural China: challenges and prospects. Washington DC: The World Bank.

Cong, Z., and M. Silverstein. 2011. Parents' depressive symptoms and support from sons and daughters in rural China. International Journal of Social Welfare 20(1): 4-17.

Cong, Z., and M. Silverstein. 2012. Caring for grandchildren and intergenerational support in rural China: a gendered extended family perspective. Ageing and Society 32(3): 425-450.

Cong, Z., and M. Silverstein. 2014. Parents' preferred care-givers in rural China: gender, migration and intergenerational exchanges. Ageing and Society 34(5): 727-757.

Croll, E., J. 2008. 'The Intergenerational Contract in the Changing Asian Family', in Goodman, Harper, S. (eds) Ageing in Asia, London and New York: Routledge, pp. 100-118.

Davin, D. (1976) Woman-work: Women and the Party in Revolutionary China. Oxford: Clarendon Press.

Davis, D. and Harrell, S. (1993) Chinese Families in the Post-Mao Era. Stanford University Press.

Fan, C. 2003. Rural-urban migration and gender division of labor in China. International Journal of Urban and Regional Research 27(1): 24-47.

Fan, C. 2007. China on the move: migration, the state, and the household. London and New York: Routledge.

Finch, J. (1989) Family Obligations and Social Change. Cambridge: Polity Press.

Gabb, J. (2008) Researching Intimacy in Families. Palgrave.

Guo, M., I. Chi, and M. Silverstein. 2009. Intergenerational support of Chinese rural elders with migrant children: do sons' or daughters' migrations make a difference? Journal of Gerontological Social Work. 52(5): 534-554.

Hoang, L.A., and S.A.Y. Brenda. 2012. Sustaining families across transnational spaces: Vietnamese migrant parents and their left-behind children. Asian Studies Review 36(3): 307-325

Hochschild, A.R. 2000. Global care chains and emotional surplus value. In On the Edge, Living With Global Capitalism, ed. W. Hutton and A. Giddens, 130-146. London: Vintage.

Jing, J. 2004. Meal rotation and filial piety. In Filial Piety, ed. C. Ikels, 35-62. California: Stanford University Press.

Joseph, A., and D. Phillips. 1999. Ageing in rural China: impacts of increasing diversity in family and community resources. Journal of Cross-Cultural Gerontology 14: 153-168.

Lee, Y.J., and Z.Y. Xiao. 1998. Children's support for parents in urban and rural China: results from a national survey. Journal of Cross-Cultural Gerontology 13: 39-62.

Liu, J. (2016) 'Intimacy and Intergenerational Relations in Rural China', Sociology, 1-16.

Luo, B., and H. Zhan. 2012. Filial piety and functional support: understanding intergenerational solidarity among families with migrated children in rural China. Ageing International 37(1): 69-92.

Lutz, H., and E. Palenga-Mollenbeck. 2012. Care workers, care drain, and care chains: reflections on care, migration, and citizenship. Social Politics 19(1): 15-37. 
Mason, J. (2002) Qualitative Researching. Sage.

Miller, E.T. 2004. Filial daughters, filial sons: comparisons from north rural China. In Filial piety, ed. C. Ikels, 34-52 California: Stanford University Press.

Risseeuw, C. (2001) 'Policy Issues of Inclusion and Exclusion in Relation to Gender and Ageing in the South', The European Journal of Development Research, 13(2): 6-48.

Wengraf, T., P. Chamberlayne, and J. Bornat. 2002. A biographical turn in the social sciences? A British-European view. Cultural Studies-Critical Methodologies 2(2): 245-269.

Song, L., S. Li, and M.W. Feldman. 2012. Out-migration of young adults and gender division of intergenerational support in rural China. Research on Aging 34(4): 399-424.

Thomas, C. 1993. Deconstructing concepts of care. Sociology 27(4): 649-669.

Ungerson, C. (ed.). 1990. Gender and caring: work and welfare in Britain and Scandinavia. London: Harvester

Tronto, Joan (2011) A feminist democratic ethics of care and global care workers. Citizenship and responsibility. In: Mahon R and Robinson F (eds.). Feminist Ethics and social policy: towards a new global political economy of care. Vancouver: UBC Press, 162-177

Wang, Weidan (2014) Ageing in China: 15 percent of the citizens are people aged 60 and over, http://wallstreetcn. com/node/77275 [accessed on 12 June 2015]. [in Chinese]

Xu, Y. 2001. Family support for old people in rural China. Social Policy \& Administration 33(3): 307-320.

Yan, Y. 2003. Private life under socialism: love, intimacy, and family change in a Chinese village 1949-1999. California: Stanford University Press

Ye, J.Z., and C. He. 2008. Lonely sunsets: the elderly left behind in rural China. Beijing: Social Science Academic Press (in Chinese).

Zhang H (2004) Living alone and the rural elderly: strategy and agency in post-Mao China. In Ikels C (ed) Filial Piety, Stanford University Press, pp.63-87.

Zhang, L. 2001. Strangers in the city: reconfigurations of space, power and social networks within China's floating population. California: Stanford University Press.

Zhang, W., S. Li, and M. Silverstein. 2005. The effects of inter-generational support on the mortality of older people in rural China. Asian Population Studies 1(3): 325-338.

Submit your manuscript to a SpringerOpen ${ }^{\circ}$ journal and benefit from:

- Convenient online submission

Rigorous peer review

- Immediate publication on acceptance

- Open access: articles freely available online

- High visibility within the field

- Retaining the copyright to your article

Submit your next manuscript at $\gg$ springeropen.com 